\title{
Correction to: The PanSurg-PREDICT Study: Endocrine Surgery During the COVID-19 Pandemic
}

K. Van Den Heede ${ }^{1} \cdot$ S. Chidambaram ${ }^{2} \cdot$ J. Winter Beatty $^{2} \cdot$ N. Chander $^{1} \cdot$ S. Markar $^{2}$. N. S. Tolley ${ }^{1,2} \cdot$ F. F. Palazzo ${ }^{1,2} \cdot$ J. K. Kinross ${ }^{2}$ A. N. Di Marco ${ }^{1,2}$ on behalf of the PanSurg Collaborative and the PREDICT-Endocrine Collaborative

Published online: 25 May 2021

(C) The Author(s) 2021

\section{Correction to: World J Surg}

https://doi.org/10.1007/s00268-021-06099-z

The PanSurg Collaborators from The Netherlands is corrected as follows:

Ewout W. Ingwersen, Floor Meijer, Anton F. Engelsman, Els J.M. Nieveen van Dijkum (Department of Surgery, Amsterdam UMC, Vrije Universiteit, Cancer Center Amsterdam, Amsterdam); Daan M. Voeten, Suzanne S. Gisbertz, Mark I. Van Berge Henegouwen (Department of
Upper Gastrointestinal Surgery, Amsterdam UMC, University of Amsterdam, Cancer Center Amsterdam, Amsterdam).

The original article has been updated.

Publisher's Note Springer Nature remains neutral with regard to jurisdictional claims in published maps and institutional affiliations.
The original article can be found online at https://doi.org/10.1007/ s00268-021-06099-z.

\section{K. Van Den Heede}

klaasvandenheede@hotmail.com

1 Department of Endocrine Surgery, Hammersmith Hospital, 72 Du Cane Rd, London W12 0HS, UK

2 Department of Surgery and Cancer, Imperial College, London, UK 